\title{
Improvement recommendations for railway infrastructure maintenance
}

\author{
Zdenka Popović ${ }^{1}$, Luka Lazarević ${ }^{1}$, Ljiljana Brajović $^{1}$, Milica Mićić ${ }^{1}$, and Nikola Mirković1 \\ ${ }^{1}$ University of Belgrade, Faculty of Civil Engineering, Bulevar kralja Aleksandra 73, 11120 Belgrade, \\ Serbia
}

\begin{abstract}
Based on the railway network performance, Infrastructure Manager is obligated to define the Maintenance plan for railway infrastructure, which contains corresponding values for intervention limits and alert limits. This paper considers vehicle response to track excitation due to the rail defect (code 2202 according to defect classification). It is indicated that theoretical models and acceleration measurements could be used to assess the quality of track geometry and ride comfort. The importance of early detection of irregularities of superstructure and substructure was emphasized. Moreover, the importance of inspection and preventive maintenance on the modern railway infrastructure was considered. According to the previous, the authors recommend nondestructive methods for inspection and early detection of irregularities of railway infrastructure.
\end{abstract}

\section{Introduction}

Interoperability of the railway system should provide the safe and uninterrupted railway traffic. Efficient maintenance is one of the preconditions for the safety of railway system. Technical Specifications for Interoperability (TSIs) are law and define the technical and operational standards, which have to be met in order to satisfy the essential requirements and to ensure the interoperability of the European railway system.

INF TSI [1] refers both to „Infrastructure“ subsystem and part of „Maintenance“ subsystem. According to [1], maintenance plan has to be defined by Infrastructure Manager (IM) for each railway line before putting it into service. The maintenance plan has to include values for Immediate Action Limits (IAL) [2], as well as the measures to be taken (speed restriction, repair time) when prescribed values are exceeded. Significant part of this maintenance plan deals with the surface irregularities on the rail head and their treatment.

The surface defect on the rail head, which is known as long-pitch corrugation (code 2202 in accordance with [3]), and its effect on the frequency of the maintenance cycle is considered in this paper. This defect occurs on the head of the inner rail in curves (Figure 1) due to the traffic load. The defect is characterised by depressions in the running surface on the rail head with the wavelength in the range $8-30 \mathrm{~cm}$.

\footnotetext{
* Corresponding author: 1lazarevic@grf.bg.ac.rs
} 


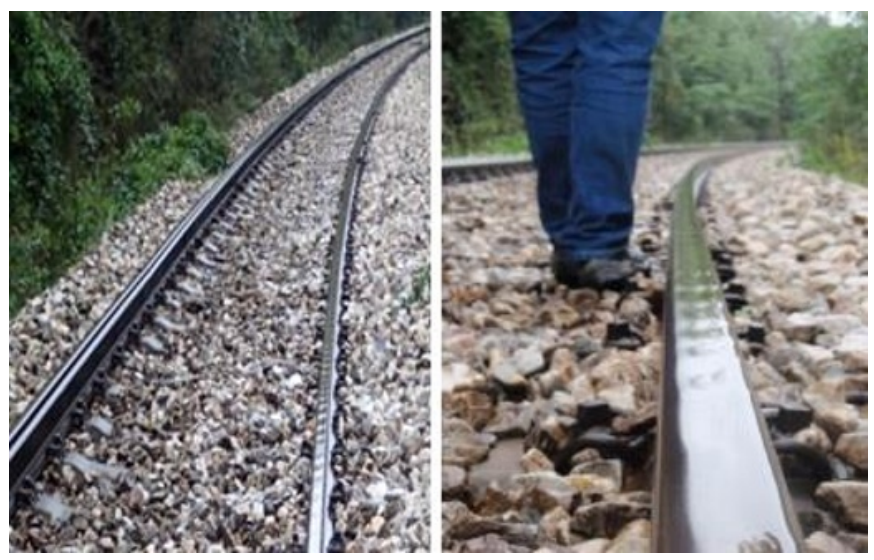

Fig. 1. Long-pitch corrugation in curve with radius $\mathrm{R}=300 \mathrm{~m}$ (railway section Resnik - Bela Reka for mixed traffic).

The paper emphasizes the influence of the vertical acceleration of unsprung masses and dynamic forces on the frequency of the maintenance cycle. The range of defect depth 0.03 $0.30 \mathrm{~mm}$ and speeds up to $200 \mathrm{~km} / \mathrm{h}$, as well as different quality of track maintenance were considered.

\section{Vertical acceleration of unsprung mass}

Rail defect type 2202 (according to [3]), can be represented by the sine function (1), as discussed in [4] and presented in Figure 2.

$$
z(x)=a \cdot \sin \left(\frac{2 \cdot \pi}{L} \cdot x\right)
$$

where:

$-z, x$ - axes of rectangular coordinate system ( $z$ is vertical and $x$ is longitudinal track axis),

$-2 a$ - depth of the defect, and

$L$ - length between successive depressions on the surface of the rail head.

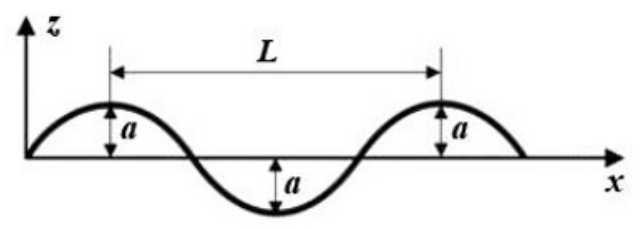

Fig. 2. Simple model of rail defect type 2202 (sine function).

Maximum vertical acceleration of unsprung mass per wheel due to the unevenness on the rail head is defined by equation (2).

$$
\ddot{z}_{\max }=a \cdot\left(\frac{2 \cdot \pi}{L} \cdot v\right)^{2}
$$

where:

$\ddot{z}_{\text {max }}$ - maximum vertical acceleration of unsprung mass per wheel (the second derivative of the sine function (1) by time) $\left[\mathrm{m} / \mathrm{s}^{2}\right]$ and

$V$ - vehicle speed in $x$ direction $[\mathrm{m} / \mathrm{s}]$. 
Table 1 shows the change in vertical acceleration depending on the vehicle speed and the length of the depression on the surface of the rail head when the defect depth is 0.03 $\mathrm{mm}$. It should be noted that the analysed depth of defect is about 10 times less than the decarburisation depth in the subsurface of the new rail (Figure 3). This confirms the importance of preventive grinding of the new rails before putting them into service.

Table 1. Maximum vertical acceleration of unsprung mass per wheel (for defect depth $0.03 \mathrm{~mm}$ ).

\begin{tabular}{|c|c|c|c|c|}
\hline$V[\mathbf{k m} / \mathbf{h}]$ & $L[\mathrm{~m}]$ & $\ddot{z}_{\max }\left[\mathrm{m} / \mathrm{s}^{2}\right]$ & $L[\mathrm{~m}]$ & $\ddot{z}_{\max }\left[\mathrm{m} / \mathrm{s}^{2}\right]$ \\
\hline 120 & \multirow{5}{*}{0.3} & 7.31 & \multirow{5}{*}{0.08} & 102.81 \\
\hline 140 & & 9.95 & & 139.93 \\
\hline 160 & & 13 & & 182.77 \\
\hline 180 & & 16.45 & & 231.32 \\
\hline 200 & & 20.31 & & 285.58 \\
\hline
\end{tabular}

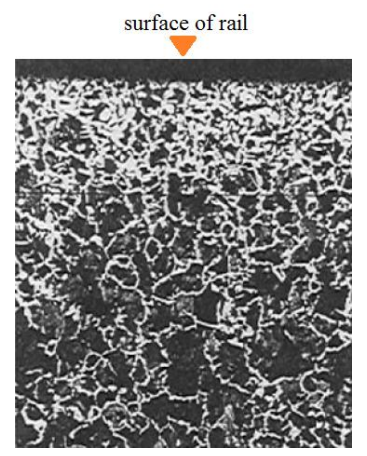

Fig. 3. Decarburisation depth up to $0.28 \mathrm{~mm}$ for steel grades R200 and R220 [5].

\section{Quasi-static axle load and track geometry deterioration}

The increase in static effects could be determined using equation (3), which was performed in accordance with the German Railway's dynamic model developed by Professor Eisenmann:

$$
Q_{\max }=(1+t \cdot n \cdot f) \cdot Q_{s} \cdot\left[\frac{p \cdot \ddot{z}_{\max }}{g}+(100-p)\right]=k \cdot Q_{s}
$$

where:

- $Q_{\max }$ - quasi-static axle load [kN],

- $Q_{s}$ - static axle load [kN],

- $k$ - coefficient of quasi-static influences,

- $t$ - statistical confidence (Table 2),

- $n$ - influence of the track quality (Table 2),

- $f$ - influence of speed and vehicle type (Table 2 ),

- $p$ - the proportion of the unsprung mass $(0.07-0.10$ for freight vehicles, 0.15 for passenger vehicles), and

- g - gravitational acceleration $\left(9.81 \mathrm{~m} / \mathrm{s}^{2}\right)$. 
Table 2 shows the values of parameters in equation (3) in accordance with [6]. IM should prescribe appropriate parameter values for specific track sections by analysing maintenance activities, as well as maintenance cost and effectiveness.

Table 2. The values of parameters in equation (3).

\begin{tabular}{|c|c|c|c|}
\hline & $n$ & $t$ & $f(V)$ \\
\hline \multirow{3}{*}{$\begin{array}{l}\text { Old } \\
\text { formula }\end{array}$} & $\begin{array}{c}0.10 \\
\text { (Excellent quality) }\end{array}$ & \multirow{6}{*}{$\begin{array}{c}1 \\
\text { (67\% confidence) } \\
2 \\
\text { (96\% confidence) } \\
3 \\
3 \\
\text { (99.7\% confidence) }\end{array}$} & \multirow{3}{*}{$\begin{array}{c}1 \\
(V \leq 60 \mathrm{~km} / \mathrm{h}) \\
1+(V-60) / 140 \\
(V>60 \mathrm{~km} / \mathrm{h})\end{array}$} \\
\hline & $\begin{array}{c}0.20 \\
\text { (Average quality) }\end{array}$ & & \\
\hline & $\begin{array}{c}0.30 \\
\text { (Poor quality) }\end{array}$ & & \\
\hline \multirow{3}{*}{$\begin{array}{l}\text { New } \\
\text { formula }\end{array}$} & $\begin{array}{c}0.15 \\
\text { (Main line) }\end{array}$ & & \multirow{3}{*}{$\begin{array}{c}1(V \leq 60 \mathrm{~km} / \mathrm{h}) \\
1+0.5 \cdot(V-60) / 140 \\
\text { (Passenger vehicles) } \\
1+0.5 \cdot(V-60) / 60 \\
\text { (Freight vehicles) }\end{array}$} \\
\hline & $\begin{array}{c}0.20 \\
\text { (Local line) }\end{array}$ & & \\
\hline & $\begin{array}{c}0.25 \\
\text { (Other line) }\end{array}$ & & \\
\hline
\end{tabular}

The exponential model of track geometry deterioration, presented with equation (4), shows that increased ballast pressure reduces the maintenance cycle.

$$
\gamma=\frac{N_{r e f}}{N_{p}}=\left[\frac{\sigma_{p}}{\sigma_{r e f}}\right]^{w}
$$

where:

- $\sigma_{\text {ref }}$ - ballast pressure due to the reference number of axle crossings $\left[\mathrm{N} / \mathrm{cm}^{2}\right]$,

- $\sigma_{p}$ - ballast pressure due to the tested number of axle crossings $\left[\mathrm{N} / \mathrm{cm}^{2}\right]$,

- $N_{\text {ref }}$ - reference number of axle crossings,

- $N_{p}$ - number of tested axle crossings,

- $w$ - referent exponent prescribed by IM for each track section, and

- 100/ $\gamma$ - reduction of track maintenance cycle [\%].

According to the engineering practice and previous considerations, the unevenness of the rail head surface could lead to the progressive deterioration of sleeper support [7], ballast material (Figure 4) and formation over time.

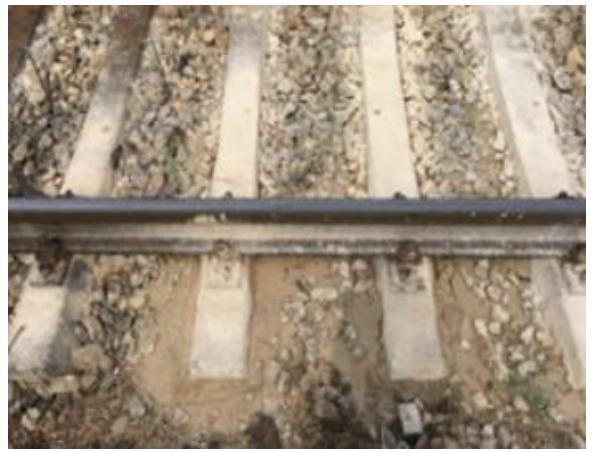

Fig. 4. Mechanism of superstructure deterioration (Pančevo Varoš station, May 2017). 


\section{Discussion and conclusion}

According to [1], the direct responsibility of Infrastructure Manager (IM) to offer prescribed (contracted with Operators) quality of railway infrastructure. In addition, IM is obliged to have a Maintenance plan containing a set of values for Intervention Limits (IL) and Alert Limits (AL). These limits are proposed as a guideline in [2]. Each IM should specify limits for his own network taking into account track alignment design, construction rules, vehicle design and the type of operation on each line. Furthermore, IM should define maintenance policy and strategy based on the available financial resources, capacity and knowledge.

Moreover, this paper presents the analysis of vertical acceleration of unsprung mass per wheel (vehicle response) due to the unevenness on the rail head (track excitation). The unevenness in rail surface (for example $0.03 \mathrm{~mm}$ or deeper) can cause significant vertical acceleration of unsprung mass with the increase in railway speed and axle load (Table 1). Therefore, the importance of inspection [8-11] and preventive maintenance on the modern railway infrastructure is essential.

On the other hand, the analysis of vehicle response to the track excitation could be used by IM in order to provide objective, quantitative statements about the relationship between track geometry quality and ride comfort at different speed levels [2]. For these considerations, a theoretical model of direct acceleration measurements could be used.

IM should develop original models for predicting the track geometry degradation, which are tailored to the specificities of the rolling stock and railway infrastructure, as well as maintenance policy.

Understanding the mechanism of deterioration of superstructure and substructure is crucial for the effective maintenance. Moreover, early detection and removal of track irregularities, which could trigger the mechanism of infrastructure deterioration, saves money and time, thus increasing the availability and competitiveness of the rail system.

Around the world, researchers are investigating the possibility of early detection of imperfections in "Infrastructure" subsystem and improving maintenance efficiency [12-20]. The authors of this paper are engaged in the development of methodology for nondestructive inspection of superstructure and substructure condition (Figure 5). Equipment presented in Figure 5 (left) is based on the measurement of electric resistance in order to assess ballast and substructure condition. Middle and right part of Figure 5 shows measurements of microtremor of sleepers in station and in plain line, according to methodology described in [7].
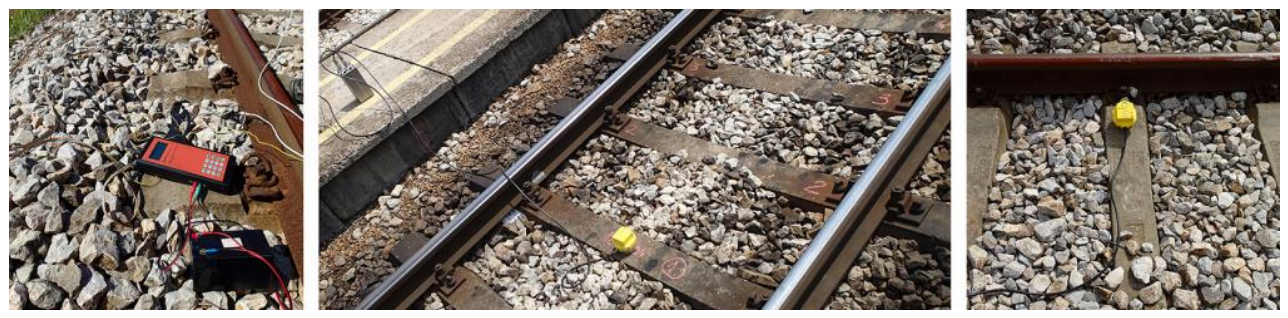

Fig. 5. Equipment for non-destructive inspection of railway infrastructure.

All maintenance activities have to ensure track quality, which correspond to the contract between IM and Operators. All measurements and inspections should be carried out in accordance to [21]. Furthermore, the control and improvement of the quality of performed maintenance activities contributes to the safety of the railway system (Figure 6). 


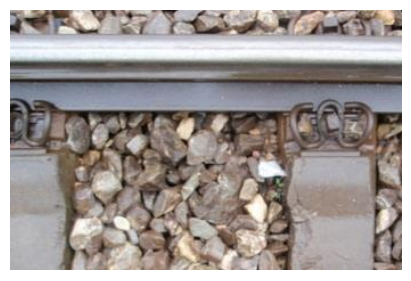

Fig. 6. Sleeper damage during track tamping (railway section Resnik - Bela Reka).

This work was supported by the Ministry of Education, Science and Technological Development of the Republic of Serbia through the research project No. 36012: "Research of technical-technological, staff and organizational capacity of Serbian Railways, from the viewpoint of current and future European Union requirements".

\section{References}

1. European Commission, Technical specifications for interoperability relating to the 'infrastructure' subsystem of the rail system in the European Union (Commission Regulation No 1299, 2014)

2. CEN, EN 13848 - Railway applications - Track - Track geometry quality - Parts 1-6.

3. UIC, Code 712 (Rail defects, 2002)

4. Z. Popović, L. Lazarević, Lj. Brajović, P. Gladović, Managing rail service life, Metalurgy 53, 4, 721-724 (2014)

5. CEN, EN 13674-1 - Railway applications - Track - Rail - Part 1: Vignole railway rails $46 \mathrm{~kg} / \mathrm{m}$ and above (2017)

6. R. Wenty, Hochleistung, Präzision und Zuverlässigkeit in der Gleisinstandhaltung, Eisenbahntechnische Rundschau 55, 6, 379-388 (2006)

7. L. Lazarević, D. Vučković, Z. Popović, Assessment of sleeper support conditions using micro-tremor analysis, P I MECH ENG F-J RAI 230, 8, 1828-1841 (2016)

8. M. Sysyn, U. Gerber, O. Nabochenko, Y. Li, V. Kovalchuk, Indicators for common crossing structural health monitoring with track-side inertial measurements, Acta Polytechnica 59, 2, 170-181 (2019)

9. M. Sysyn, O. Nabochenko, V. Kovalchuk, D. Gruen, A. Pentsak, Improvement of inspection system for common crossings by track side monitoring and prognostics, Structural Monitoring and Maintenance 6, 3, 219-235 (2019)

10. Z. Popović, L. Lazarević, Lj. Brajović, M. Vilotijević, The importance of rail inspections in the urban area - Aspect of head checking rail defects, PROCEDIA ENGINEER 117, 596-608 (2015)

11. Z. Popović, V. Radović, L. Lazarević, V. Vukadinović, G. Tepić, Rail inspection of RCF defects, Metalurgy 52, 4, 537-540 (2013).

12. L. Lazarević, D. Vučković, M. Vilotijević, Z. Popović, Application of seismic tomography for assessment of the railway substructure condition, STRUCT HEALTH MONIT 18, 3, 792-805 (2019)

13. X. Deng, Z. Li, Z. Qian, W. Zhai, Q. Xiao, R. Dollevoet, Pre-cracking development of weld-induced squats due to plastic deformation: Five-year field monitoring and numerical analysis, INT J FATIGUE 127, 431-444 (2019)

14. K. Zeng, T. Qiu, X. Bian, M. Xiao, H. Huang, Identification of ballast condition using SmartRock and pattern recognition, CONSTR BUILD MATER 221, 50-59 (2019) 
15. J. A. Zakeri, S. A. Mosayebi, M. Esmaeili, Numerical and field investigations of track dynamic behavior caused by light and heavy railway vehicles, J THEOR APPL MECH 54, 3, 871-879 (2016)

16. S. A. Mosayebi, J. A. Zakeri, M. Esmaeili, Effects of train bogie patterns on the mechanical performance of ballasted railway tracks with unsupported sleepers, P I MECH ENG F-J RAI 232, 1, 238-248 (2018)

17. P. Barkhordari, R. Galeazzi, M. Blanke, Prognosis of railway ballast degradation for turnouts using track-side accelerations, P I MECH ENG O-J RIS (2020)

18. Y. Çati, S. Gökçeli, Ö. Anil, C. S. Korkmaz, Experimental and numerical investigation of usp for optimization of transition zone of railway, ENG STRUCT (2019)

19. T. Watanabe, K. Goto, K. Matsuoka, S. Minoura, Validation of a dynamic wheel load factor and the influence of various track irregularities on the dynamic response of prestressed concrete sleepers, P I MECH ENG F-J RAI (2019)

20. W. Bai, Q. Sun, F. Wang, R. Liu, R. An, A segmental evaluation model for determining residual rail service life based on a discrete-state conditional probabilistic method, P I MECH ENG O-J RIS 233, 2, 211-225 (2019)

21. CEN, EN 13231-1 - Railway applications - Track - Acceptance of works - Part 1: Works on ballasted track - Plain line, switches and crossings (2014) 